Check for updates

Cite this: RSC Adv., 2019, 9, 1889

Received 18th September 2018

DOI: $10.1039 / c 8 r a 07758 d$

rsc.li/rsc-advances Accepted 23rd December 2018

\section{Highly efficient redox reaction between potassium permanganate and 3,3',5,5'-tetramethylbenzidine for application in hydrogen peroxide based colorimetric assays $\uparrow$}

\author{
Ying Sun, ${ }^{\text {abc }}$ Hui Liu, ${ }^{e}$ Xionghong Tan, ${ }^{\text {abc }}$ Zheng Li, ${ }^{d}$ Yanlin Du, ${ }^{\text {abc }}$ Aixian Zheng, ${ }^{\text {bc }}$ \\ Xiaolong Liu (D) ${ }^{* b c}$ and Niancai Peng ${ }^{\star d}$
}

\begin{abstract}
Potassium permanganate $\left(\mathrm{KMnO}_{4}\right)$ is one of the most important oxidants, which plays important roles in many fields. Here, we found that $\mathrm{KMnO}_{4}$ could directly induce the oxidation of $3,3^{\prime}, 5,5^{\prime}$ tetramethylbenzidine (TMB) to generate an oxidized product with a color change. This redox reaction is highly efficient, and $1 \mu \mathrm{M} \mathrm{KMnO}_{4}$ is enough to cause detectable changes in the absorbance signal. Meanwhile, this reaction is very fast and the generated blue product can stabilize for a relatively long period, which has great advantages in practical applications. Since hydrogen peroxide $\left(\mathrm{H}_{2} \mathrm{O}_{2}\right)$ is able to react with $\mathrm{KMnO}_{4}$ under acidic conditions, the $\mathrm{KMnO}_{4}-\mathrm{TMB}$ system can be used for the detection of $\mathrm{H}_{2} \mathrm{O}_{2}$; the absorbance signal induced by $5 \mu \mathrm{M} \mathrm{H}_{2} \mathrm{O}_{2}$ can be easily detected in this method. Meanwhile, the $\mathrm{KMnO}_{4}$-TMB system can also be used for the detection of glucose by monitoring the generation of $\mathrm{H}_{2} \mathrm{O}_{2}$, which is the main product of glucose oxidation; this method permits detection of concentrations as low as $10 \mu \mathrm{M}$ glucose, and the sensitivity is comparable to or higher than most peroxidase mimetic based methods, but avoiding the preparation and storage of the nanomaterials. Furthermore, the $\mathrm{KMnO}_{4}-\mathrm{TMB}$ system can even be used for analyzing glucose in serum samples, which can also be expected to be used in immunoassays.
\end{abstract}

\section{Introduction}

The development of simple, fast and cost-effective bioassays for the detection of disease related biomarkers plays important roles in biomedical application. Natural enzymes show high catalytic activity and substrate specificity, which have been applied to various fields, such as food safety, environmental analysis, biotechnology and biomedicine. For example, horseradish peroxidase (HRP) has been widely used in enzyme linked immunosorbent assay (ELISA), which can be conjugated with antibodies for the detection of specific proteins through an HRP

${ }^{a}$ College of Life Science, Fujian Agriculture and Forestry University, Fuzhou 350002, P. R. China

${ }^{b}$ Fujian Institute of Research on the Structure of Matter, Chinese Academy of Sciences, Fuzhou 350002, P. R. China.E-mail: zax040500273@126.com; xiaoloong.liu@gmail. com

${ }^{c}$ The United Innovation of Mengchao Hepatobiliary Technology Key Laboratory of Fujian Province, Mengchao Hepatobiliary Hospital of Fujian Medical University, Fuzhou 350025, P. R. China

${ }^{d}$ State Key Laboratory for Manufacturing Systems Engineering, School of Mechanical Engineering, Xi'an Jiaotong University, Xi'an 710054, P. R. China. E-mail: pnc@ mail.xjtu.edu.cn

${ }^{e}$ Fifth People's Hospital, Ganzhou City, Jiangxi Province, China

$\dagger$ Electronic supplementary information (ESI) available. See DOI: 10.1039/c8ra07758d mediated color reaction. However, the catalytic activity of natural enzymes is highly related to the environmental conditions during measurement, such as $\mathrm{pH}$ and temperature. Furthermore, the strict conditions and high cost of their preparation and storage could further limit their applications. ${ }^{1-3}$

To overcome these shortcomings, recent efforts have been devoted to develop simple and efficient enzymatic mimics. Up to now, a variety of nanomaterials have been reported to exhibit peroxidase-like catalytic activities, such as magnetic nanomaterials, ${ }^{4,5}$ carbon nanomaterials, ${ }^{6-8}$ metal-organic frameworks (MOFs), ${ }^{\mathbf{9}, 10}$ and so on.,11-16 Compared with natural enzymes, these peroxidase mimetics exhibit obviously improved stability and design flexibility, which can be applied in different biosensing applications. It is also reported that some nanomaterials ${ }^{17}$ such as $\mathrm{V}_{2} \mathrm{O}_{5}$ nanosheets, ${ }^{18} \mathrm{MnO}_{2}$ nanosheets ${ }^{19,20}$ and cobalt oxyhydroxide nanoflakes, ${ }^{\mathbf{2 1 , 2 2}}$ exhibited intrinsic oxidation ability, which can directly induce the oxidation of $3,3^{\prime}, 5,5^{\prime}$-tetramethylbenzidine (TMB) to generate the oxidant product with color change. These reactions are fast and highly efficient, which can be further used for the detection of many biomolecules.

Although lot of efforts have been devoted to the nanomaterial based methods, there are still some deficiencies that limit their applications, such as complicated preparation, the 
uniformity and stability of the nanomaterials. Meanwhile, the catalytic sites of the enzymatic mimics are always on their surfaces, which might be easily blocked by nonspecific proteins or other biomolecules. In this way, the catalytic activities of the enzymatic mimics would be significantly reduced, and thus further reduce the sensitivity of these enzymatic mimic based sensors.

Potassium permanganate $\left(\mathrm{KMnO}_{4}\right)$ is one of the most important oxidants, which plays important roles in many fields. In this paper, we found that $\mathrm{KMnO}_{4}$ can directly induce the oxidation of TMB to generate the oxidized product with significant color change. Meanwhile, the reaction is very fast and the generated blue product can be stable for a relatively long period. It is well known that hydrogen peroxide $\left(\mathrm{H}_{2} \mathrm{O}_{2}\right)$ is able to reaction with $\mathrm{KMnO}_{4}$ in acidic conditions, and thus causing the consumption of $\mathrm{KMnO}_{4}$. In this way, the $\mathrm{KMnO}_{4}$-TMB system can be used for the detection of $\mathrm{H}_{2} \mathrm{O}_{2}$. Meanwhile, the $\mathrm{KMnO}_{4}$ TMB system can be also used for the indirectly detection of other biomolecules by monitoring the generation of $\mathrm{H}_{2} \mathrm{O}_{2}$.

Glucose is the main energy source for human body, which plays important roles in cell growth. The concentration of glucose in blood is closely associated with hypoglycemia or diabetes, which can be also used for monitoring many other diseases. Thus, accurate measurement of glucose is of great importance. ${ }^{23-25}$ As we know, glucose oxidase (GOx) can catalyze the oxidation of glucose in the presence of oxygen, accompanying the formation of gluconic acid and $\mathrm{H}_{2} \mathrm{O}_{2} \cdot{ }^{6,8}$ Thus, the proposed $\mathrm{KMnO}_{4}$-TMB system also can be used for the detection of glucose by monitoring the generation of $\mathrm{H}_{2} \mathrm{O}_{2}$. Scheme 1 depicts the principle of $\mathrm{KMnO}_{4}$-TMB system for glucose detection.

\section{Experimental}

\section{Materials and apparatus}

TMB, $\beta$-lactose, ascorbic acid and uric acid were purchased from Aladdin Reagent Co. Ltd. (China). Glucose, sucrose and galactose were purchased from Sigma-Aldrich Chemical Co. (USA). GOx was purchased from J \& K Chemical Ltd. (China). All other reagents were of analytical grade and obtained from Sinopharm Chemical Reagent co. Ltd. (China), such as $\mathrm{KMnO}_{4}$, $\alpha$-lactose and $\mathrm{H}_{2} \mathrm{O}_{2}$. Ultrapure water used in this experiment was obtained from a Millipore water purification system (Milli-

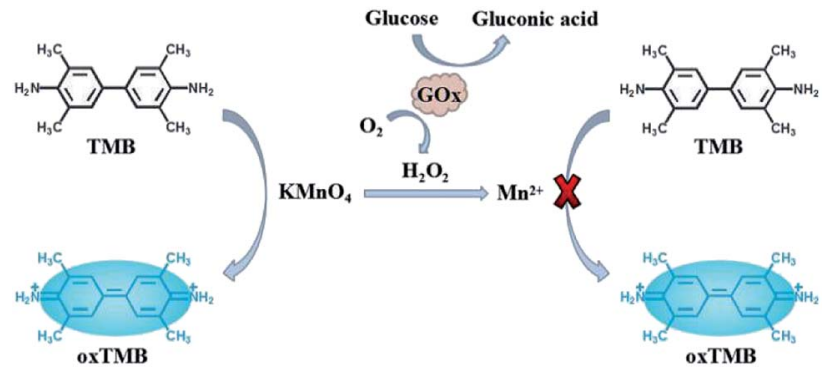

Scheme 1 Highly efficient redox reaction between $\mathrm{KMnO}_{4}$ and $\mathrm{TMB}$ for application in $\mathrm{H}_{2} \mathrm{O}_{2}$ based colorimetric detection of glucose.
Q). The absorption signals in this experiment were measured by microplate reader (Spectra Max M5, Molecular Devices).

\section{The highly efficient redox reaction between $\mathrm{KMnO}_{4}$ and TMB}

TMB solution was prepared by dissolving in ethanol. To verify the redox reaction between $\mathrm{KMnO}_{4}$ and $\mathrm{TMB}$, the absorption spectra of $20 \mu \mathrm{M} \mathrm{KMnO}, 200 \mu \mathrm{M}$ TMB and their mixture between $350 \mathrm{~nm}$ and $750 \mathrm{~nm}$ were measured. To investigate the influence of $\mathrm{pH}$ on the redox reaction, the absorption spectra of $\mathrm{KMnO}_{4}$-TMB system prepared in $10 \mathrm{mM}$ PBS buffer with different $\mathrm{pH}$ values $(2,2.5,3,3.5,4,4.5,5,5.5,6,6.5$ and 7$)$ were measured. To obtain the optimal concentration of TMB, the absorption spectra of $\mathrm{KMnO}_{4}(20 \mu \mathrm{M})$ after reaction with different concentrations of TMB $(0,25,50,100,200,250$ and 500 $\mu \mathrm{M})$ were measured. We also measured the absorption spectra of the corresponding solution after addition of sulfuric acid to further oxidize the oxidized TMB. Finally, to investigate the stability of the oxidized product, we also measured the absorption spectra of $20 \mu \mathrm{M} \mathrm{KMnO}_{4}$ solution after addition of $200 \mu \mathrm{M}$ TMB for different times.

\section{The $\mathrm{KMnO}_{4}$-TMB system for $\mathrm{H}_{2} \mathrm{O}_{2}$ detection}

To verify the reaction between $\mathrm{KMnO}_{4}$ and $\mathrm{H}_{2} \mathrm{O}_{2}$, the absorption spectra of $0.2 \mathrm{mM} \mathrm{KMnO}_{4}$ after reaction with different concentrations of $\mathrm{H}_{2} \mathrm{O}_{2}(0,0.1,1$ and $10 \mathrm{mM})$ were measured. For the detection of $\mathrm{H}_{2} \mathrm{O}_{2}, 8 \mu \mathrm{L}$ of $0.5 \mathrm{mM} \mathrm{KMnO}_{4}$ was firstly reacted with different concentrations $(0,5,10,20,40,80,100$ and $200 \mu \mathrm{M}$ ) of $\mathrm{H}_{2} \mathrm{O}_{2}$ in $10 \mathrm{mM}$ PBS buffer ( $\mathrm{pH}$ 5.5) for $5 \mathrm{~min}$. Then, $8 \mu \mathrm{L}$ of $5 \mathrm{mM}$ TMB was added into above solutions. The absorption spectra of these solutions between $350 \mathrm{~nm}$ and $750 \mathrm{~nm}$ were measured by microplate reader. The calibration curve for $\mathrm{H}_{2} \mathrm{O}_{2}$ sensing was made by using the absorbance intensity at $652 \mathrm{~nm}$ as the ordinate and the concentration of $\mathrm{H}_{2} \mathrm{O}_{2}$ as the abscissa.

\section{The $\mathrm{KMnO}_{4}$-TMB system for glucose detection}

The $\mathrm{KMnO}_{4}$-TMB system also can be used for glucose detection by monitoring the generation of $\mathrm{H}_{2} \mathrm{O}_{2}$. For glucose detection, 4 $\mu \mathrm{L}$ of $0.1 \mathrm{mg} \mathrm{mL}{ }^{-1}$ GOx was mixed with $50 \mu \mathrm{L}$ of different concentrations of glucose in 0.5 mM PBS ( $\mathrm{pH} 7.0)$. After incubated at $37^{\circ} \mathrm{C}$ for $30 \mathrm{~min}, 130 \mu \mathrm{L}$ of $10 \mathrm{mM}$ PBS buffer (pH 5.5), 8 $\mu \mathrm{L}$ of $0.5 \mathrm{mM} \mathrm{KMnO}_{4}$ and $8 \mu \mathrm{L}$ of $5 \mathrm{mM}$ TMB were added into above solution. Then, the absorption spectra of these solutions between $350 \mathrm{~nm}$ and $750 \mathrm{~nm}$ were measured by microplate reader. The calibration curve for glucose sensing was made by using the absorbance intensity at $652 \mathrm{~nm}$ as the ordinate and the concentration of glucose as the abscissa. To investigate the specificity of this method, $1 \mathrm{mM}$ other sugars such as sucrose, $\beta$ lactose, $\alpha$-lactose and galactose, were used instead of $0.1 \mathrm{mM}$ glucose under the same condition for glucose detection.

\section{Analysis of glucose in serum sample}

The serum samples were obtained from Mengchao Hepatobiliary Hospital of Fujian Medical University, which was diluted by $0.5 \mathrm{mM}$ PBS buffer (pH 7.0). The study was approved 
by the Medical Ethics Committee of Mengchao Hepatobiliary Hospital of Fujian Medical University, and the written consent was received from all participants in this study. The detection of glucose in serum sample was realized as follows: $4 \mu \mathrm{L}$ of $0.1 \mathrm{mg}$ $\mathrm{mL}^{-1}$ GOx was mixed with $50 \mu \mathrm{L}$ of 100 times diluted serum and different concentrations of glucose in $0.5 \mathrm{mM}$ PBS ( $\mathrm{pH} 7.0$ ). After incubated at $37^{\circ} \mathrm{C}$ for $30 \mathrm{~min}, 122 \mu \mathrm{L}$ of $10 \mathrm{mM}$ PBS buffer (pH 5.5), $16 \mu \mathrm{L}$ of $0.5 \mathrm{mM} \mathrm{KMnO}_{4}$ and $8 \mu \mathrm{L}$ of $5 \mathrm{mM}$ TMB were added into above solution. Then, the absorption spectra of these solutions between $350 \mathrm{~nm}$ and $750 \mathrm{~nm}$ were measured by microplate reader. The calibration curve for glucose sensing was made by using the absorbance intensity at $652 \mathrm{~nm}$ as the ordinate and the concentration of the added glucose as the abscissa. The added concentrations of glucose varied from 20 $\mu \mathrm{M}$ to $800 \mu \mathrm{M}$. The concentration of glucose in serum sample was estimated by the standard addition method.

\section{Results and discussion}

\section{The highly efficient redox reaction between $\mathrm{KMnO}_{4}$ and TMB}

To verify the redox reaction between $\mathrm{KMnO}_{4}$ and TMB, the absorption spectra of $\mathrm{KMnO}_{4}$, TMB and their mixture were measured. As shown in Fig. $1 \mathrm{~A}, \mathrm{KMnO}_{4}$ and $\mathrm{TMB}$ themselves exhibited extremely low absorbance signal (curve a and b). However, upon the addition of TMB, the $\mathrm{KMnO}_{4}$ solution had significant absorbance enhancement at $652 \mathrm{~nm}$ (curve c), which is consistent with the characteristic absorption peak of oxidized TMB. This result indicated that $\mathrm{KMnO}_{4}$ can directly induce the oxidation of TMB to generate the oxidized product with significant color change. This reaction can be also confirmed by the photograph of corresponding solution shown in Fig. 1A.

In order to obtain the best reaction efficiency, we optimized the reaction condition. To investigate the influence of $\mathrm{pH}$ on the redox reaction, the absorption spectra of $\mathrm{KMnO}_{4}$-TMB system prepared in $10 \mathrm{mM}$ PBS buffer with different $\mathrm{pH}$ values were measured. As shown in Fig. S1 in the ESI, $\dagger$ the reaction efficiency was obviously affected by the $\mathrm{pH}$ value of the buffer. In more acidic conditions, the absorption peak of the $\mathrm{KMnO}_{4}-\mathrm{TMB}$ system shifted to $450 \mathrm{~nm}$, which may be due to the further oxidation of oxidized TMB. It is reported that the oxidized TMB can be further oxidized to a yellow diimine after addition of sulfuric acid, with the maximum absorption peak at $450 \mathrm{~nm}$. This process can be also confirmed by the results shown in
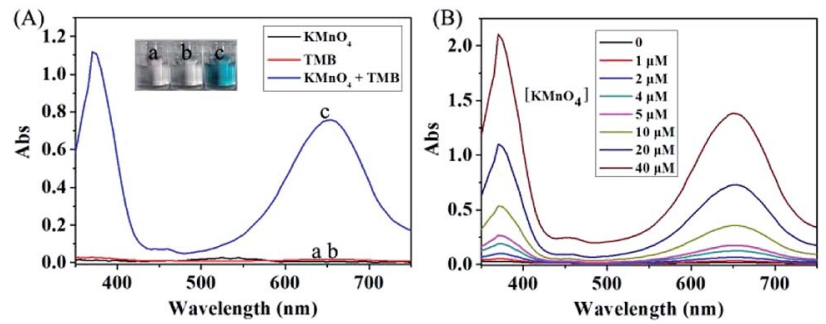

Fig. 1 (A) The absorption spectra of different solutions: (a) $20 \mu \mathrm{M}$ $\mathrm{KMnO}_{4}$; (b) $200 \mu \mathrm{M} \mathrm{TMB}$; (c) $20 \mu \mathrm{M} \mathrm{KMnO}_{4}+200 \mu \mathrm{M} \mathrm{TMB}$. (B) The absorption spectra of different concentrations of $\mathrm{KMnO}_{4}$ after reaction with $200 \mu$ M TMB.
Fig. S1B in the ESI. $\uparrow$ The best $\mathrm{pH}$ value of PBS buffer is 5.5 due to its best absorbance signal.

To optimize the concentration of TMB, the absorption spectra of $\mathrm{KMnO}_{4}$ after reaction with different concentrations of TMB were measured in the optimized buffer. As shown in Fig. S2 in the ESI, $\uparrow$ TMB at low concentration could be partly oxidized to yellow oxide. When the concentration of TMB up to $200 \mu \mathrm{M}$, TMB could be mainly oxidized to blue oxide. While further increase the concentration of TMB, the absorbance signal might slightly decrease. After comparison, the optimal concentration of TMB is $200 \mu \mathrm{M}$ due to its best absorbance signal. We also investigate the stability of the oxidized product by measuring the absorption spectra of $\mathrm{KMnO}_{4}$ solution after addition of $200 \mu \mathrm{M}$ TMB for different times. As shown in Fig. S3 in the ESI, $\uparrow$ there is no significant difference in the absorbance signals at different times. This data indicated that the redox reaction between $\mathrm{KMnO}_{4}$ and TMB is very fast, and the experimental result can be stable for a relatively long period, which have great advantages in practical applications.

In the optimized condition, we measured the absorption spectra of different concentrations of $\mathrm{KMnO}_{4}$ solution after reaction with $200 \mu \mathrm{M}$ TMB. As shown in Fig. 1B, the absorbance signal increased by increasing the concentration of $\mathrm{KMnO}_{4}$. This redox reaction is highly efficient due to that $1 \mu \mathrm{M}$ of $\mathrm{KMnO}_{4}$ was enough to cause the detectable change in absorbance signal.

\section{The $\mathrm{KMnO}_{4}$-TMB system for $\mathrm{H}_{2} \mathrm{O}_{2}$ detection}

It is well known that $\mathrm{H}_{2} \mathrm{O}_{2}$ is able to reaction with $\mathrm{KMnO}_{4}$ in acidic condition, and thus causing the consumption of $\mathrm{KMnO}_{4}$. In this way, the $\mathrm{KMnO}_{4}$-TMB system can be used for the detection of $\mathrm{H}_{2} \mathrm{O}_{2}$. We first used the absorbance data to verify the reaction between $\mathrm{KMnO}_{4}$ and $\mathrm{H}_{2} \mathrm{O}_{2} \cdot \mathrm{KMnO}_{4}$ has two large absorption peaks at $525 \mathrm{~nm}$ and $545 \mathrm{~nm}$, and its solution is purple. After reaction with $\mathrm{H}_{2} \mathrm{O}_{2}$, the absorbance of the solution obviously reduced, accompanied by the color fading to colorless (Fig. 2A). This phenomenon can confirm the reaction between $\mathrm{KMnO}_{4}$ and $\mathrm{H}_{2} \mathrm{O}_{2}$. Based on this reaction, the $\mathrm{KMnO}_{4}-\mathrm{TMB}$ system could be used for the detection of $\mathrm{H}_{2} \mathrm{O}_{2}$.

As shown in Fig. 2B, the $\mathrm{KMnO}_{4}$-TMB system exhibited high absorbance at $652 \mathrm{~nm}$. When $\mathrm{H}_{2} \mathrm{O}_{2}$ was introduced, the absorbance intensity of the solution significantly reduced, accompanied by the color fading from blue to colorless. We also
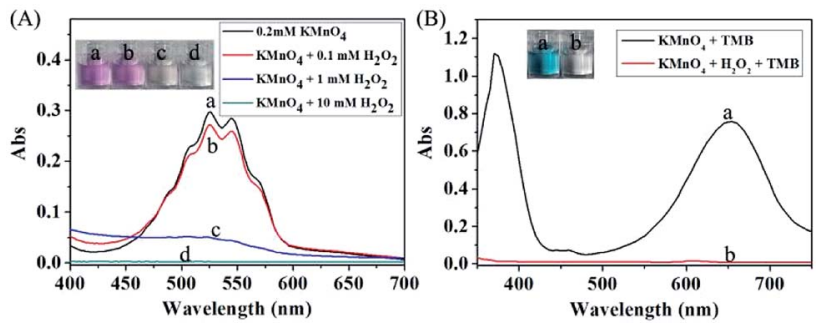

Fig. 2 (A) The absorption spectra of $0.2 \mathrm{mM} \mathrm{KMnO}_{4}$ after reaction with different concentrations of $\mathrm{H}_{2} \mathrm{O}_{2}$. (B) The absorption spectra of different solutions: (a) $20 \mu \mathrm{M} \mathrm{KMnO}_{4}+200 \mu \mathrm{M} \mathrm{TMB}$; (b) $20 \mu \mathrm{M} \mathrm{KMnO}_{4}$ $+0.5 \mathrm{mM} \mathrm{H}_{2} \mathrm{O}_{2}+200 \mu \mathrm{M} \mathrm{TMB}$. 
measured the absorption spectra of the $\mathrm{KMnO}_{4}$-TMB system for analyzing different concentrations of $\mathrm{H}_{2} \mathrm{O}_{2}$. As shown in Fig. 3, the absorbance intensity of the system gradually decreased by increasing the concentration of added $\mathrm{H}_{2} \mathrm{O}_{2}$. Meanwhile, the absorbance intensity at $652 \mathrm{~nm}$ was linear to the concentration of $\mathrm{H}_{2} \mathrm{O}_{2}$ in the range from 5 to $100 \mu \mathrm{M}$, with a calibration function of $y=-0.005 x+0.7375\left(R^{2}=0.9976\right)$. This redox reaction based method permits detection of $5 \mu \mathrm{M} \mathrm{H}_{2} \mathrm{O}_{2}$.

\section{The $\mathrm{KMnO}_{4}$-TMB system for glucose detection}

The $\mathrm{KMnO}_{4}$-TMB system also can be used for the indirectly detection of other biomolecules by monitoring the generation or consumption of $\mathrm{H}_{2} \mathrm{O}_{2}$. It is well known that $\mathrm{GOx}$ can catalyze the oxidation of glucose in the presence of oxygen, resulting in the formation of $\mathrm{H}_{2} \mathrm{O}_{2}$. Thus, the detection of glucose could be realized by using the $\mathrm{KMnO}_{4}$-TMB system. We first use the absorbance data to investigate the viability of this method. As shown in Fig. 4A, the $\mathrm{KMnO}_{4}$-TMB system exhibited high absorbance at $652 \mathrm{~nm}$. When only addition of glucose or GOx, the absorbance signal of the system was little influenced. If glucose was first reacted with GOx and then introduced to the $\mathrm{KMnO}_{4}$-TMB system, the absorbance of the solution significantly reduced, accompanied by the color fading from blue to colorless. This phenomenon confirmed that the $\mathrm{KMnO}_{4}$-TMB system can be used for the detection of glucose.

We then measured the absorption spectra of the $\mathrm{KMnO}_{4}{ }^{-}$ TMB system for analyzing different concentrations of glucose. As shown in Fig. 4B, the $\mathrm{KMnO}_{4}$-TMB system exhibited high absorbance at $652 \mathrm{~nm}$ when only addition of GOx. When glucose was introduced, the absorbance intensity of the system slowly decreased by increasing the concentration of added glucose. Meanwhile, the reduced absorbance intensity at $652 \mathrm{~nm}$ was linear to the concentration of glucose in the range from 10 to $400 \mu \mathrm{M}$, with a calibration function of $y=0.0016 x+$ $0.0049\left(R^{2}=0.9981\right)$. The detection limit of this method was calculated to be $4.55 \mu \mathrm{M}$, which gave a net signal equal to three times the standard deviation of the background. As shown in Table S1 in the ESI, $\dagger$ this sensitivity is comparable to many other nanomaterials based methods, but avoiding the preparation and storage of the nanomaterials. ${ }^{6,9,26-34}$

To investigate the specificity of this method, $1 \mathrm{mM}$ other sugars (sucrose, $\beta$-lactose, $\alpha$-lactose and galactose) were used
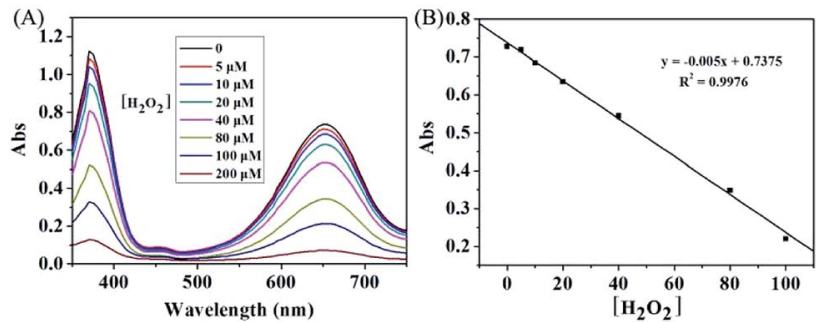

Fig. 3 (A) The absorption spectra of the $\mathrm{KMnO}_{4}-\mathrm{TMB}$ system for analyzing different concentrations of $\mathrm{H}_{2} \mathrm{O}_{2}$. (B) Calibration curve of $\mathrm{H}_{2} \mathrm{O}_{2}$ in the range from 5 to $100 \mu \mathrm{M}$. The data shown here represent the average of three independent experiments.
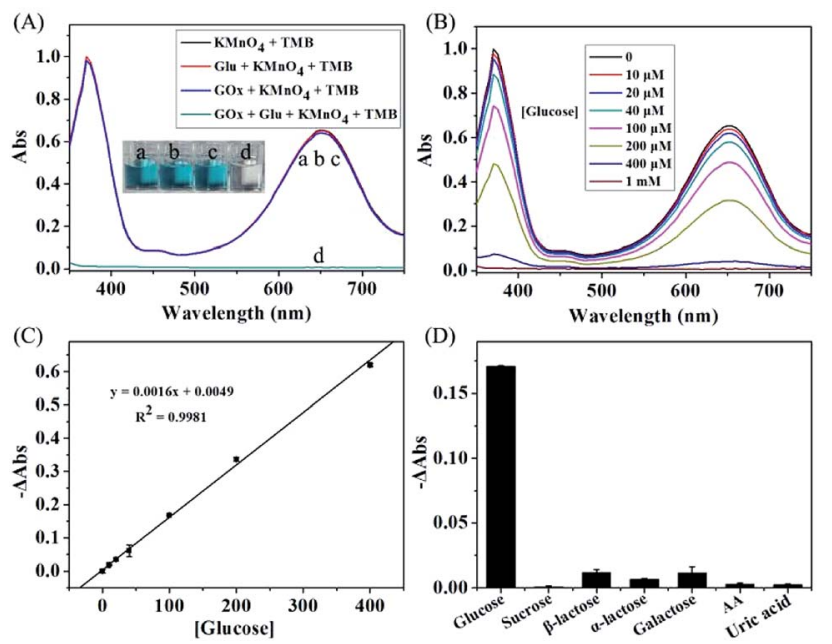

Fig. 4 (A) The absorption spectra of $\mathrm{KMnO}_{4}-\mathrm{TMB}$ system upon addition of the below solution: (a) control; (b) glucose (1 mM); (c) GOx (2 $\mu \mathrm{g} \mathrm{mL}^{-1}$ ); (d) glucose reacted with GOx for $30 \mathrm{~min}$. (B) The absorption spectra of the $\mathrm{KMnO}_{4}$-TMB system for analyzing different concentrations of glucose. (C) Calibration curve of glucose in the range from 10 to $400 \mu \mathrm{M}$. (D) Absorbance changes ( $-\Delta$ Abs) of the system for analyzing glucose $(100 \mu \mathrm{M})$, other sugars (sucrose, $\beta$ lactose, $\alpha$-lactose and galactose, each at $1 \mathrm{mM}$ ) and other interferences (ascorbic acid and uric acid, each at $100 \mu \mathrm{M}$ ). The data shown here represent the average of three independent experiments.

instead of $0.1 \mathrm{mM}$ glucose under the same condition for glucose detection. As shown in Fig. 4C, the system showed obvious absorbance decrease when analyzing $0.1 \mathrm{mM}$ of glucose. While, the absorbance signals of the system were scarcely influenced by other sugars even at ten times of the concentration of glucose. The other interferences, such as ascorbic acid and uric acid, have also been investigated. The absorbance signals of the system were scarcely changed, when GOx was added to initiate the reaction. Thus, the proposed $\mathrm{KMnO}_{4}-\mathrm{TMB}$ system can show high selectivity for glucose detection.

\section{Analysis of glucose in real sample}

The concentration of glucose in blood is closely associated with hypoglycemia or diabetes, which can be also used for monitoring many other diseases. Thus, accurate measurement of glucose is of great importance. To investigate the feasibility of $\mathrm{KMnO}_{4}$-TMB system for practical application, we further use the proposed method for analyzing glucose in serum sample, which obtained from Mengchao Hepatobiliary Hospital of Fujian Medical University. Fig. 5A showed the absorption spectra of the $\mathrm{KMnO}_{4}$-TMB system for analyzing diluted serum with addition of GOx and different concentrations of glucose. The absorbance signal of the system slowly decreased by increasing the concentration of spiked glucose. Meanwhile, the reduced absorbance intensity at $652 \mathrm{~nm}$ was linear to the concentration of spiked glucose, with a calibration function of $y=0.0002 x+$ $0.0089\left(R^{2}=0.9954\right)$. We then used a standard addition method to estimate the concentration of glucose in serum. After calculation, the concentration of glucose in diluted serum was 44.5 $\mu \mathrm{M}$. Thus, the actual concentration of glucose in serum sample 

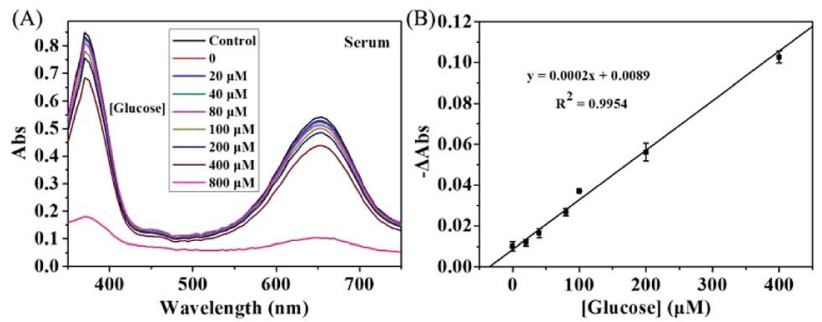

Fig. 5 The absorption spectra of the $\mathrm{KMnO}_{4}-\mathrm{TMB}$ system for analyzing diluted serum with addition of different concentrations of glucose $(0,20,40,80,100,200,400$ and $800 \mu \mathrm{M}$, respectively). (B) Calibration curve of glucose sensing in diluted serum using the reduced absorbance intensity $(-\Delta \mathrm{Abs})$ as the ordinate and the concentrations of added glucose as the abscissa. The data shown here represent the average of three independent experiments.

was $4.45 \mathrm{mM}$, which agreed with the fact that the normal level of glucose in blood is between 3.9 and $6.1 \mathrm{mM}^{35}$ It is worth mentioning that the GOx does not affect the redox reaction between $\mathrm{KMnO}_{4}$ and TMB, when the concentration of GOx was lower than $2 \mu \mathrm{g} \mathrm{mL} \mathrm{mL}^{-1}$. Meanwhile, $10 \mathrm{ng} \mathrm{mL}^{-1}$ of GOx was enough to cause the detectable absorbance signal (Fig. S4 in the ESI $\dagger$ ). Therefore, the $\mathrm{KMnO}_{4}$-TMB system can be also expected to be used in immunoassays by combining antibody and GOx, and thus further expand its applications.

\section{Conclusions}

In this study, we have designed a novel $\mathrm{KMnO}_{4}$-TMB system for $\mathrm{H}_{2} \mathrm{O}_{2}$ based colorimetric assay based on the $\mathrm{KMnO}_{4}$ induced oxidation of TMB, that could generate oxidized blue product. The designed system is very fast, stable and highly efficient due to that $1 \mu \mathrm{M}$ of $\mathrm{KMnO}_{4}$ is enough to induce the detectable change in absorbance signal. The current system can be used for the detection of $\mathrm{H}_{2} \mathrm{O}_{2}$ by the consumption of $\mathrm{KMnO}_{4}$, and also can be used for the detection of glucose even in serum sample by monitoring the generation of $\mathrm{H}_{2} \mathrm{O}_{2}$, which permits detection of as low as $10 \mu \mathrm{M}$ glucose that is comparable to or lower than most peroxidase mimetic based methods, but avoiding the preparation and storage of the nanomaterials. Taking together, this highly efficient redox reaction between $\mathrm{KMnO}_{4}$ and TMB might be further expected to food safety, environmental analysis, clinical diagnosis and other fields.

\section{Conflicts of interest}

There are no conflicts to declare.

\section{Acknowledgements}

This work was supported by the National Natural Science Foundation of China (Grant No. 21705022, 61675164 and 61827827), the Natural Science Foundation of Fujian Province (Grant No. 2016J05207), and the Joint Funds for the Innovation of Science and Technology of Fujian Province (Grant No. 2017Y9115).

\section{Notes and references}

1 H. Wei and E. Wang, Chem. Soc. Rev., 2013, 42, 6060-6093.

2 Y. Lin, J. Ren and X. Qu, Acc. Chem. Res., 2014, 47, 1097-1105.

3 Q. Wang, H. Wei, Z. Zhang, E. Wang and S. Dong, TrAC, Trends Anal. Chem., 2018, 105, 218-224.

4 L. Gao, J. Zhuang, L. Nie, J. Zhang, Y. Zhang, N. Gu, T. Wang, J. Feng, D. Yang, S. Perrett and X. Yan, Nat. Nanotechnol., 2007, 2, 577-583.

5 X. Sun, S. Guo, C. S. Chung, W. Zhu and S. Su, Adv. Mater., 2013, 25, 132-136.

6 Y. Song, K. Qu, C. Zhao, J. Ren and X. Qu, Adv. Mater., 2010, 22, 2206-2210.

7 Q. Wang, J. Lei, S. Deng, L. Zhang and H. Ju, Chem. Commun., 2013, 49, 916-918.

8 A. X. Zheng, Z. X. Cong, J. R. Wang, J. Li, H. H. Yang and G. N. Chen, Biosens. Bioelectron., 2013, 49, 519-524.

9 H. Chen, Q. Qiu, S. Sharif, S. Ying, Y. Wang and Y. Ying, ACS Appl. Mater. Interfaces, 2018, 10, 24108-24115.

10 H. Cheng, Y. Liu, Y. Hu, Y. Ding, S. Lin, W. Cao, Q. Wang, J. Wu, F. Muhammad, X. Zhao, D. Zhao, Z. Li, H. Xing and H. Wei, Anal. Chem., 2017, 89, 11552-11559.

11 Z. Tian, J. Li, Z. Zhang, W. Gao, X. Zhou and Y. Qu, Biomaterials, 2015, 59, 116-124.

12 L. Han, C. Li, T. Zhang, Q. Lang and A. Liu, ACS Appl. Mater. Interfaces, 2015, 7, 14463-14470.

13 C. Lu, X. Liu, Y. Li, F. Yu, L. Tang, Y. Hu and Y. Ying, ACS Appl. Mater. Interfaces, 2015, 7, 15395-15402.

14 X. Jiang, C. Sun, Y. Guo, G. Nie and L. Xu, Biosens. Bioelectron., 2015, 64, 165-170.

15 A. Zheng, X. Zhang, J. Gao, X. Liu and J. Liu, Anal. Chim. Acta, 2016, 941, 87-93.

16 Y. W. Wang, S. Tang, H. H. Yang and H. Song, Talanta, 2016, 146, 71-74.

17 W. Wang, L. Wang, F. An, H. Xu, Z. Yin, S. Tang, H. H. Yang and H. Song, Anal. Chim. Acta, 2017, 980, 72-78.

18 A. B. Ganganboinaa and R. Doonga, Sens. Actuators, B, 2018, 273, 1179-1186.

19 J. Pal and T. Pal, RSC Adv., 2016, 6, 83738-83747.

20 W. Lai, Q. Zeng, J. Tang, M. Zhang and D. Tang, Microchim. Acta, 2018, 185, 92.

21 D. Ji, Y. Du, H. Meng, L. Zhang, Z. Huang, Y. Hu, J. Li, F. Yu and Z. Li, Sens. Actuators, B, 2018, 256, 512-519.

22 Y. Ding, J. Zhao, B. Li, X. Zhao, C. Wang, M. Guo and Y. Lin, Microchim. Acta, 2018, 185, 131.

23 J. W. Liu, Y. Luo, Y. M. Wang, L. Y. Duan, J. H. Jiang and R. Q. Yu, ACS Appl. Mater. Interfaces, 2016, 8, 33439-33445.

24 L. Ding, Z. Gong, M. Yan, J. Yu and X. Song, Microchim. Acta, 2017, 184, 4531-4536.

25 S. P. Nichols, A. Koh, W. L. Storm, J. H. Shin and M. H. Schoenfisch, Chem. Rev., 2013, 113, 2528-2549.

26 H. Wei and E. Wang, Anal. Chem., 2008, 80, 2250-2254.

27 L. Hu, Y. Yuan, L. Zhang, J. Zhao, S. Majeed and G. Xu, Anal. Chim. Acta, 2013, 762, 83-86.

28 X. Liu, S. Zhang, P. Tan, J. Zhou, Y. Huang, Z. Nie and S. Yao, Chem. Commun., 2013, 49, 1856-1858. 
29 Y. Jv, B. Li and R. Cao, Chem. Commun., 2010, 46, 8017-8019. 30 J. Liu, X. Hu, S. Hou, T. Wen, W. Liu, X. Zhu, J. J. Yin and X. Wu, Sens. Actuators, B, 2012, 166, 708-714.

31 T. Lin, L. Zhong, L. Guo, F. Fu and G. Chen, Nanoscale, 2014, 6, 11856-11862.

32 T. M. Chen, X. J. Wu, J. X. Wang and G. W. Yang, Nanoscale, 2017, 9, 11806-11813.
33 M. Li, L. Liu, Y. Shi, Y. Yang, H. Zheng and Y. Long, New J. Chem., 2017, 41, 7578-7582.

34 Y. M. Wang, J. W. Liu, J. H. Jiang and W. Zhong, Anal. Bioanal. Chem., 2017, 409, 225-4232.

35 J. L. Ma, B. C. Yin, X. Wu and B. C. Ye, Anal. Chem., 2016, 89, 1323-1328. 